Çukurova Üniversitesi Mühendislik Mimarlık Fakültesi Dergisi, 32(2), ss.153-160, Haziran 2017

Çukurova UniversityJournal of theFaculty of Engineeringand Architecture, 32(2), pp. 153-160, June 2017

\title{
En Aw 5754 (Almg3) Alüminyum Alaşımının Frezelenmesi İşleminde Kesme Parametrelerinin Yüzey Pürüzlülüğüne Etkisinin İncelenmesi
}

\author{
Mustafa Kemal KULEKC $\dot{I}^{1}$, Uğur EŞME ${ }^{1}$, Abdul Kadir EKŞi் ${ }^{* 2}$, \\ Zülfü KOÇOĞLU ${ }^{1}$, Necip Fazıl YILMAZ ${ }^{3}$ \\ ${ }^{I}$ Mersin Üniversitesi, Tarsus Teknoloji Fakültesi, Otomotiv Mühendisliği Bölümü, Tarsus, \\ Mersin \\ ${ }^{2}$ Çukurova Üniversitesi, Mühendislik Mimarlık Fakültesi, Makine Mühendisliği Bölümü, Adana \\ ${ }^{3}$ Gaziantep Üniversitesi, Mühendislik Mimarlık Fakültesi, Makine Mühendisliği Bölümü, \\ Gaziantep
}

Geliş tarihi: 13.03.2017 Kabul tarihi: 31.05.2017

$\ddot{\mathbf{O} z}$

Bu çalışmada, endüstriyel uygulamalarda kullanım alanları giderek artmakta olan EN AW $5754\left(\mathrm{AlMg}_{3}\right)$ Alüminyum alaşımının yüzey frezeleme işlenmesinde, devir sayısı, ilerleme kesici elmas uç yarıçapı, talaş derinliği değerlerinin yüzey pürüzlülüğüne etkisi deneysel olarak incelenmiştir. Deneyler, devir sayısı (1330-1500 dev/dak), ilerleme (97-196 mm/dak), kesici elmas uç yarıçapı (1-2 mm), kesme derinliği (1-1,5 mm) ile soğutma sıvısı (bor yağı) yerine dizel kullanılarak üniversal freze tezgâhında yapılmıştır. İş parçasının yüzey kalitesinin, yüzey pürüzlülük tablosunda 4. ve 10. deneylerde kullanılan parametrelerin daha iyi sonuçlar verdiği tespit edilmiştir. Bu sonucun kesici uç yarıçapının büyük olması ile elde edildiği saptanmıştır. Yapılan çalışmanın sonuçları; frezeleme işleminde elde edilmek istenilen yüzey pürüzlülüğü ile işlem parametreleri arasında optimizasyon yapılması gerektiğini ortaya koymaktadir.

Anahtar Kelimeler: Alüminyum alaşımı, Yüzey pürüzlülüğü, Yüzey işleme, Optimizasyon

\section{Investigation of Milling Process Parameters for the Optimization of Surface Roughness of EN AW 5754 (AIMg3) Aluminum Alloy}

\begin{abstract}
In this study, the effects of milling process parameters; such as feed rate, revolution per minute, chip thickness and radius of cutting tool on surface roughness experimentally investigated. Experiments performed using the parameters in the range of 1330-1500 rpm rotating speed, $97-196 \mathrm{~mm} / \mathrm{min}$ feed rate, $1-2 \mathrm{~mm}$ radius cutting tool tip, $1-1,5 \mathrm{~mm}$ chip thickness. Diesel fuel was used as a lubricant oprevent adhesion of the chip to the machined surface. Optimum surface roughness results were obtained with increasing the radius of cutting tool. The results of the study reveal that cutting parameter optimization is needed to obtain required surface roughness.
\end{abstract}

Keywords: Aluminum alloy, Surface roughness, Surface machining, Optimization

*Sorumlu yazar (Corresponding author): Abdul Kadir EKŞİ, akeksi@cu.edu.tr 


\section{GíRiş}

Makine imalat endüstrisinde işlenmiş parçaların yüzey kalitesinin iyi olması, kalitenin yükseltilmesine olanak sağlaması sebebiyle tercih edilmektedir. Yüzey pürüzlülüğü; özellikle pistonsilindir mekanizmalarında, yataklar, dişliler gibi birbirine sürtünerek çalışan makine parçaları üzerinde önemli derecede etkilidir. Talaşlı imalat yöntemlerinde; malzemenin cinsi, kesici takım, kesme hızı ve ilerleme, kesme derinliği, soğutma sıvısı ve tezgâhın konstrüksiyonu gibi pek çok faktör, yüzey pürüzlülüğünü etkiler. $\mathrm{Bu}$ faktörlerden birinin değişmesi ile yüzey pürüzlülüğü de değişebilmektedir. Ancak değişmeye neden olan faktörlerin etkileri birbirinden farklı ve bağımsız olabileceği gibi, birbirlerine bağımlı da olabilmektedir [1-7].

Deney tasarımı, araştırmacılar tarafından bir sistemi ya da belirli bir süreci tanımlamak ve anlamak için kullanılmaktadır. Deney tasarımı ile sistemin girdilerinde değişiklik yapılarak çıktıların gözlemlenmesi ve analiz edilmesi amaçlanır. Deneyler, araştırmacılar tarafından bir sistemi veya belirli bir süreci tanımlamak ve anlamak için kullanılmaktadır. Deneysel tasarım üründeki kaliteyi ürünün tasarım aşamasında sağlamayı amaçlamaktadır. Deneysel tasarım ilk olarak 1920'lerde İngiliz istatistikçi R. A. Fisher ve arkadaşları tarafından geliştirilmiştir [8].

İstatistiksel deney tasarımının amacı minimum zaman, kaynak ve maliyet ile maksimum anlamlı veriler elde etmektir. Bundan dolayı geleneksel yöntemlerden uzak ve araştırmalara yeni bir yaklaşım getirmektedir. Geleneksel deney tasarımı yöntemleri yüksek maliyet, uzun zaman ve kaynak gerektiren yöntemlerdir. Ayrıca geleneksel yöntemler ile yapılan deneysel çalışmalarda parametreler arasındaki etkileşimler göz ard1 edilmektedir. Tüm bu dezavantaj ve kısıtlamalar istatistiksel deney tasarımı yöntemi ile giderilebilmektedir. İstatistiksel deney tasarımında çalışmanın amacı ve olanaklar dahilinde farklı yöntemler kullanılmaktadır. Bunlar; tam faktöriyel deney tasarımı, kesirli faktöriyel deney tasarımı ve Taguchi metodu olarak siralanabilirler $[9,10]$.
İki veya daha fazla parametre ve bu parametrelere ait en az iki veya daha fazla seviyelerin bulunduğu deneylerde, seviyelerin birbirleri ile çarpımları sonucu oluşan kombinasyon düzeni esas alınarak yapılan deneysel çalışmalara tam faktöriyel (tam eşlendirmeli) deney tasarımı adı verilmektedir. Bilimsel olarak deney tasarımı 3 temel prensibe dayandırılmaktadır. Bunlar; deney tekrarı, deney sırasının rastgele yapılması ve deneyin bloklaşması olarak tanımlanmaktadır. Tam faktöriyel (tam eşlendirmeli) deney tasarımında rastsal tam bloklaşmalar kullanılmaktadır. Bloklaşmanın temel amacı bilinmeyen ve kontrol edilemeyen hataların deneyi etkilemesini önlemektir. Eğer bu temel prensipler yerine getirilmezse deneyde bilinmedik hataların ortaya çıkması muhtemel olmaktadır. Deney esnasında oluşabilecek hatalardan ve sapmalardan sakınmak için iki yöntem kullanılmaktadır. Bunlar; deneylerin rastgele yapılması ve geriye dönük detayların incelenerek gerekli düzeltmelerin yapılması olarak siralanabilmektedir [11, 12].

Yapılan çalışmada $\mathrm{AlMg}_{3}$ koduyla bilinen alüminyum malzemenin yüzeyi çeşitli işleme parametreleriyle elde edilen pürüzlülük değerlerinin parametreler arası birbirleriyle etkileşimleri incelenmiştir. Elde edilen veriler tablo ve grafiklere yansıtılarak farklı sonuçlar elde edilmiştir. $\mathrm{AlMg}_{3}$ alüminyum alaşımının paslanmaya karşı dirençli, ağırlıkça çok hafif olması mekanik özelikleri açısından istenilen değerlerde olması nedeniyle Otomotiv sanayisinde kulanım alanları artmaktadır.

$\mathrm{Bu}$ çalışmada $\mathrm{AlMg}_{3}$ koduyla bilinen alüminyum malzemenin üniversal freze tezgâhında 16 farklı deney sonuçları değerlendirilerek yüzey pürüzlülüğüne devir sayısı, ilerleme, kesme derinliğinin etkileri deneysel olarak incelenmiştir. Yapılan çalışmanın bu alanda çalışan araştırmacılar ile endüstrideki mühendislere katk1 sağlayacağı değerlendirilmektedir.

\section{MATERYAL VE METOT}

Deneysel çalışmalarda EN AW 5754 $\left(\mathrm{AlMg}_{3}\right)$ Alüminyum alaşımı plakaların yüzey frezeleme işlemi Şekil 1'de verilen First LC 20 
VHS Universal Kalıpçı Freze tezgâhında gerçekleştirilmiştir. Frezeleme işlemleri $1 \mathrm{~mm}$ $2 \mathrm{~mm}$ yarıçaplı iki farklı geometriye sahip tpkn 2204 pdr sert metal elmas uçlar ile gerçekleştirilmiştir. Frezelenen yüzeylerin pürüzlülük değerleri çözünürlüğü +-\% 2 olan Mitotoyo SJ 201 yüzey pürüzlülük ölçüm cihazı ile ölçülmüştür. Deneysel çalışmalarda kullanılan $\mathrm{AlMg}_{3}$ Alüminyum alaşımı malzemenin kimyasal bileşimi ve mekanik özellikleri Çizelge 1 ve Çizelge 2'de verilmiştir.

EN AW $5754\left(\mathrm{AlMg}_{3}\right)$ Alüminyum alaşımı düşük seviye dayanıma sahip olup, korozyon dayanımı yüksek, kaynak edilebilme, soğuk şekillendirme özellikleri iyidir.
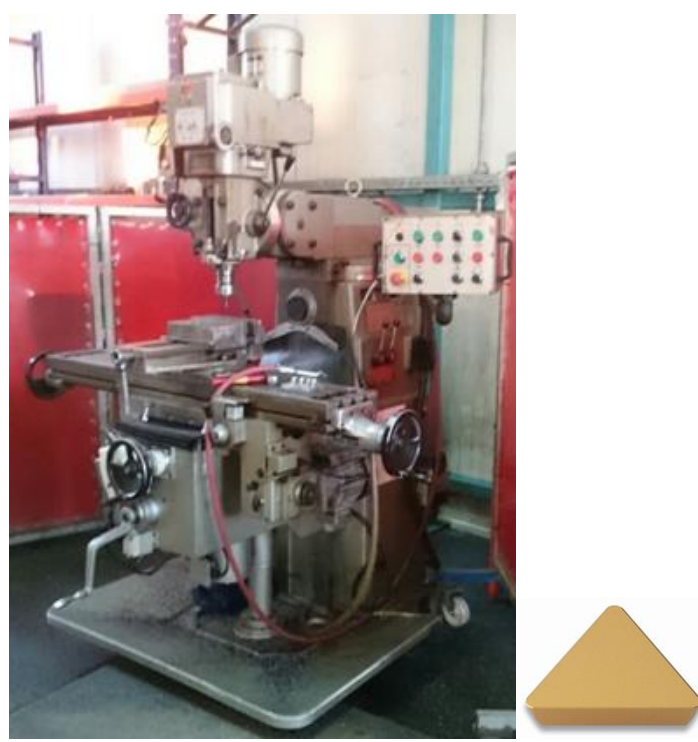

Şekil 1. Deneysel çalışmalarda kullanılan freze tezgâhı ve sert metal elmas uç

Talaşlı imalat endüstrisinde takım tezgâhlarında kesme işlemi genellikle Şekil 2'de görüldüğü gibi soğutma veya yağlama amaçlı kullanılan kesme sıvıları ile yapılmaktadır. Yapmış olduğumuz çalıșmada kesme sıvısı yerine alüminyum üzerinde talaş kaldırma işleminde yüzeyden kaldırılan talaşın yüzeye sıvanarak yüzey pürüzlülügüüü olumsuz yönde etkilemesinin önüne geçmek amacıyla, kesme sıvılarına nazaran yağlama özelliği daha iyi olan dizel ile yağlama işlemi yapılmıştır.
Çizelge 1. EN AW $5754 \quad\left(\mathrm{AlMg}_{3}\right)$ alüminyum alaşımı plakaların kimyasal özellikleri

\begin{tabular}{|c|c|c|c|c|}
\hline \multicolumn{5}{|c|}{ Kimyasal Bileşimi } \\
\hline $\mathrm{Fe}$ & $\mathrm{Si}$ & $\mathrm{Cu}$ & $\mathrm{Mn}$ & $\mathrm{Mg}$ \\
\hline 0,4 & 0,4 & 0,1 & 0,5 & $2,6-3,6$ \\
\hline $\mathrm{Zn}$ & $\mathrm{Cr}$ & $\mathrm{Ti}$ & Diğer & $\mathrm{Al}$ \\
\hline 0,2 & 0,3 & 0,15 & 0,15 & Kalan \\
\hline
\end{tabular}

Çizelge 2. EN AW $5754 \quad\left(\mathrm{AlMg}_{3}\right)$ alüminyum alaşımı plakaların mekanik özellikleri

\begin{tabular}{|c|c|c|c|c|}
\hline \multicolumn{5}{|c|}{ Mekanik Özellikleri } \\
\hline Temper & $\begin{array}{c}\text { Akma } \\
\text { Mukavemeti }\end{array}$ & $\begin{array}{c}\text { Cekme } \\
\text { Mukavemeti }\end{array}$ & Uzama & Sertlik \\
\hline- & (MPa) & (MPa) & $\mathbf{- 5 0 \%}$ & (brinel) \\
\hline- & min-max & min-max & min-max & min-max \\
\hline 0/H111 & $80-100$ & $190-215$ & 24 & $50-55$ \\
\hline HX2 & $130-185$ & $220-245$ & 14 & $65-70$ \\
\hline HX4 & $160-215$ & $240-270$ & 12 & $73-75$ \\
\hline HX6 & $190-245$ & $265-290$ & 9 & 80 \\
\hline HX8 & $250-270$ & $290-315$ & 8 & $85-90$ \\
\hline HX9 & 300 & 340 & $0-4$ & 95 \\
\hline
\end{tabular}

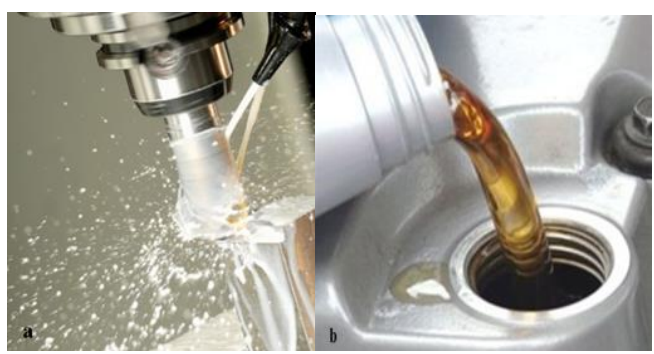

Şekil 2. a) Talaş kaldırma işlemlerinde kullanılan kesme sıvis1, b) Deneysel frezeleme işleminde yağlayıcı olarak kullanılan dizel

Şekil 3'te Tezgâh tablasına bağlanan alüminyum plaka ve 3 adet sert metal elmaslı kesici takım ile Frezeleme işleminde sıvanmayı önlemek amacıyla malzeme yüzeyine talaş kaldırma işleminden önce dizel uygulaması görülmektedir. Farklı ilerleme, devir sayısı, kesme derinliği ve kesici yarıçapı değerleriyle 20x30x180 ebatlarında 8 adet Alüminyum plaka üzerinde arkalı önlü toplamda 16 deney numunesinde yüzey pürüzlülük değerlerini incelemek amaciyla frezeleme işlemeleri gerçekleştirilmiştir. 
En Aw 5754 (Almg3) Alüminyum Alaşımının Frezelenmesi Işleminde Kesme Parametrelerinin Yüzey Pürüzlülügüne Etkisinin Incelenmesi

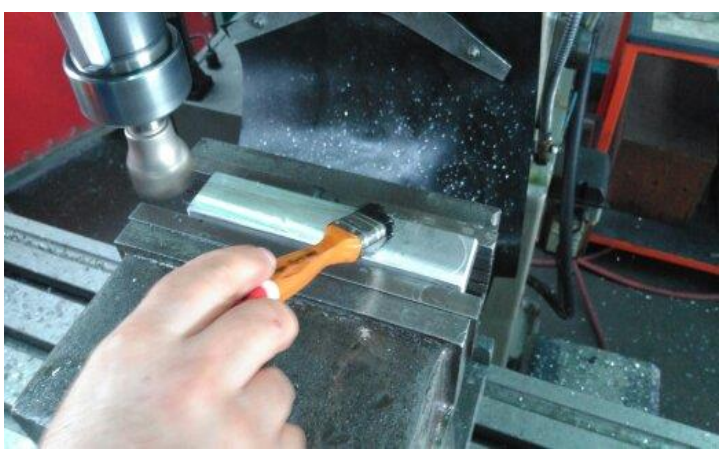

Şekil 3. Parça yüzeyine talaş kaldırma işleminden önce dizel uygulaması

\section{BULGULAR}

Çizelge 3'te normal olasılık grafikleri (NOG) elde etmek amacıyla çalışmada kullanılan frezeleme işlemine ait 4 farklı parametre ve iki farklı düzeye ait değerler için verilmiştir. Çizelge 4'te 4 farklı parametre ve iki farklı düzey ile gerçekleştirilmiş olan frezeleme işleminde elde edilen yüzeyler üzerinde yapılan ölçümler ile elde edilen yüzey pürüzlülük değerleri $\mathrm{Ra}, \mathrm{sRz}, \mathrm{Rq}$ cinsinden verilmiştir. Şekil 4 de farklı kesici uç yarıçapı ile gerçekleştirilen frezeleme işleminde elde edilen talaş oluşumlarına ait görüntülere yer verilmiştir.

Çizelge 3. Deneysel çalışmada kullanılmış olan frezeleme işlemine ait 4 farklı parametre ve iki farklı düzey

\begin{tabular}{|c|c|c|c|c|c|}
\hline Düzey & $\begin{array}{c}\text { A } \\
\text { Devir Sayıs1 } \\
(\text { dev/dak })\end{array}$ & $\begin{array}{c}\text { B } \\
\text { İlerleme } \\
(\mathrm{mm} / \text { dak })\end{array}$ & $\begin{array}{c}\text { C } \\
\text { Talaş derinliği } \\
(\mathrm{mm})\end{array}$ & $\begin{array}{c}\text { D } \\
\text { Kesici } \\
\text { yarıçap1 } \\
(\mathrm{mm})\end{array}$ & $\begin{array}{c}\text { E } \\
\text { Sembol }\end{array}$ \\
\hline Alt & 1330 & 97 & 1 & 1 & - \\
\hline Üst & 1500 & 196 & 1,5 & 2 & + \\
\hline
\end{tabular}

Çizelge 4. Frezeleme işlemine ait 4 farklı parametre ve iki farklı düzey ile elde edilen yüzey pürüzlülüğüne ait sonuçlar

\begin{tabular}{|c|c|c|c|c|c|c|c|}
\hline \multicolumn{2}{|c|}{ İki Düzeyli Dört Faktörlü Deney Tablosu } & \multicolumn{2}{c|}{ Yüzey Pürüzlülü̆̈̈ $(\mu \mathrm{m})$} \\
\hline $\begin{array}{c}\text { Deney } \\
\text { no }\end{array}$ & $\begin{array}{c}\text { Devir sayısı } \\
\text { dev/dak }\end{array}$ & $\begin{array}{c}\text { İlerleme } \\
\text { mm/dak }\end{array}$ & $\begin{array}{c}\text { Kesme } \\
\text { derinliği } \\
\text { mm }\end{array}$ & $\begin{array}{c}\text { Kesici uç } \\
\text { yarıçap1 } \\
\text { mm }\end{array}$ & Ra & Rz & Rq \\
\hline 1 & 1330 & 97 & 1 & 1 & 0,81 & 3,82 & 0,97 \\
\hline 2 & 1330 & 97 & 1 & 2 & 2,6 & 12,3 & 3,22 \\
\hline 3 & 1330 & 97 & 1,5 & 1 & 0,81 & 4,06 & 0,98 \\
\hline 4 & 1330 & 97 & 1,5 & 2 & 0,3 & 2,4 & 0,38 \\
\hline 5 & 1330 & 196 & 1 & 1 & 2,43 & 10,1 & 2,82 \\
\hline 6 & 1330 & 196 & 1 & 2 & 1,09 & 4,6 & 1,22 \\
\hline 7 & 1330 & 196 & 1,5 & 1 & 2,3 & 9,62 & 2,68 \\
\hline 8 & 1330 & 196 & 1,5 & 2 & 1 & 4,2 & 1,14 \\
\hline 9 & 1500 & 97 & 1 & 1 & 0,63 & 2,65 & 0,74 \\
\hline 10 & 1500 & 97 & 1 & 2 & 0,44 & 2,46 & 0,54 \\
\hline 11 & 1500 & 97 & 1,5 & 1 & 0,65 & 3,19 & 0,77 \\
\hline 12 & 1500 & 97 & 1,5 & 2 & 0,38 & 2,36 & 0,47 \\
\hline 13 & 1500 & 196 & 1 & 1 & 1,79 & 7,78 & 2,12 \\
\hline 14 & 1500 & 196 & 1 & 2 & 0,83 & 3,76 & 0,96 \\
\hline 15 & 1500 & 196 & 1,5 & 1 & 1,87 & 764 & 2,18 \\
\hline 16 & 1500 & 196 & 1,5 & 2 & 0,91 & 4,21 & 1,06 \\
\hline
\end{tabular}



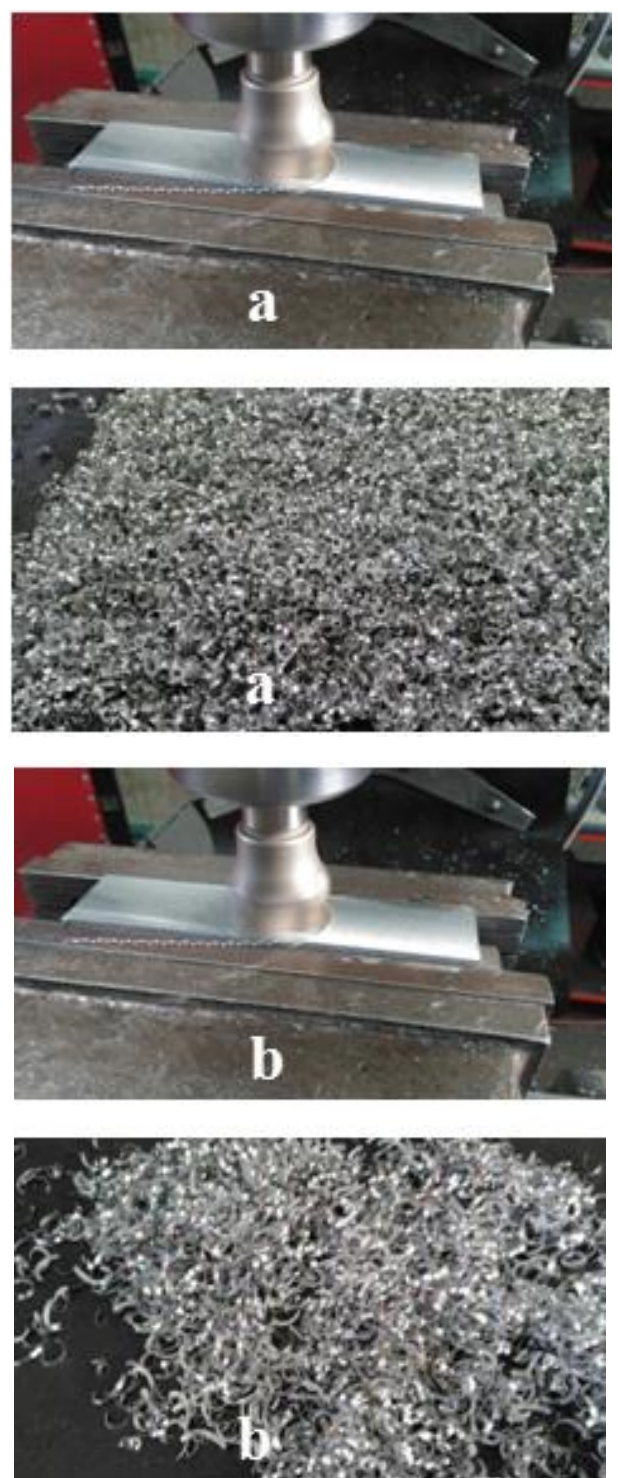

Şekil 4. a) $1 \mathrm{~mm}$ kesici uç yarıçapı ile gerçekleştirilen frezeleme işleminde elde edilen talaş oluşumları, b) $2 \mathrm{~mm}$ kesici uç yarıçapı ile gerçekleştirilen frezeleme işleminde elde edilen talaş oluşumları

İstatistiksel açıdan kontrol edilmeyen fakat deney sırasında kendiliğinden değişen faktörlerin kalite değişeni Y’ye (yüzey pürüzlülüğüne) olası etkilerini elimine etmek amaciyla uygulama sırasının Çizelge 5'de verilen standart sıra yerine rastsal olarak belirlenmesi gerekir.
Çizelge 5. Frezeleme işlemine ait 4 farklı parametre ve iki farklı düzey ile rastsal sıralama ile elde edilen yüzey pürüzlülüğg̈ne ait sonuçlar

\begin{tabular}{|c|c|c|c|c|c|c|}
\hline $\begin{array}{c}\text { Standart } \\
\text { sira }\end{array}$ & $\begin{array}{c}\text { Rastsal } \\
\text { Srra }\end{array}$ & $\begin{array}{c}\mathbf{A} \\
\text { Devir } \\
\text { Sayısı } \\
\text { dev/dak }\end{array}$ & $\begin{array}{c}\text { B } \\
\text { Ilerleme } \\
\text { mm/dak }\end{array}$ & $\begin{array}{c}\text { C } \\
\text { Talas } \\
\text { Derinliği } \\
\text { mm }\end{array}$ & $\begin{array}{c}\mathbf{D} \\
\text { Kesici } \\
\text { uç } \\
\text { yarı́apı } \\
\text { mm }\end{array}$ & $\begin{array}{c}\mathbf{Y} \\
\text { Yüzey } \\
\text { Pürüzlülü } \\
\text { ğu }(\mu \mathrm{m})\end{array}$ \\
\hline 1 & 5 & 1330 & 196 & 1 & 1 & 2,43 \\
\hline 2 & 9 & 1500 & 97 & 1 & 1 & 0,63 \\
\hline 3 & 2 & 1330 & 97 & 1 & 2 & 2,6 \\
\hline 4 & 11 & 1500 & 97 & 1,5 & 1 & 0,65 \\
\hline 5 & 16 & 1500 & 196 & 1,5 & 2 & 0,91 \\
\hline 6 & 8 & 1330 & 196 & 1,5 & 2 & 1 \\
\hline 7 & 1 & 1330 & 97 & 1 & 1 & 0,81 \\
\hline 8 & 14 & 1500 & 196 & 1 & 2 & 0,83 \\
\hline 9 & 6 & 1330 & 196 & 1 & 2 & 1,09 \\
\hline 10 & 13 & 1500 & 196 & 1 & 1 & 1,79 \\
\hline 11 & 10 & 1500 & 97 & 1 & 2 & 0,44 \\
\hline 12 & 4 & 1330 & 97 & 1,5 & 2 & 0,3 \\
\hline 13 & 7 & 1330 & 196 & 1,5 & 1 & 2,3 \\
\hline 14 & 15 & 1500 & 196 & 1,5 & 1 & 1,87 \\
\hline 15 & 3 & 1330 & 97 & 1,5 & 1 & 0,81 \\
\hline 16 & 12 & 1500 & 97 & 1,5 & 2 & 0,38 \\
\hline
\end{tabular}

Çizelge 6'da Faktörlerin düzey değerleri ile deneyin uygulanması sonucu elde edilen Y (yüzey pürüzlülük) gözlem değerleri rastsal sırada verilmektedir.

Çizelge 6. Parametrelerin düzey değerleri ile Y (yüzey pürüzlülük) gözlem değerleri rastsal sirada

\begin{tabular}{|c|c|c|c|c|c|c|c|c|c|c|c|c|c|c|}
\hline \multicolumn{15}{|c|}{ DİZAYN MATRİSİ } \\
\hline \multirow{2}{*}{$\begin{array}{c}\text { Standart } \\
\text { Sira }\end{array}$} & \multicolumn{14}{|c|}{ Etkiler } \\
\hline & A & B & C & D & $\mathrm{AB}$ & AC & $\mathrm{AD}$ & $\mathrm{BC}$ & BD & $\mathrm{CD}$ & $\mathrm{ABC}$ & $A B D$ & $\mathrm{ACD}$ & $\mathrm{BCD}$ \\
\hline 1 & - & - & - & - & + & + & + & + & + & + & - & - & - & - \\
\hline 2 & - & - & - & + & + & + & - & + & - & - & - & + & + & + \\
\hline 3 & - & - & + & - & + & - & + & - & + & - & + & - & + & + \\
\hline 4 & - & - & + & + & + & - & - & - & - & + & + & + & - & - \\
\hline 5 & - & + & - & - & - & + & + & - & - & + & + & + & - & + \\
\hline 6 & - & + & - & + & - & + & - & - & + & - & + & - & + & - \\
\hline 7 & - & + & + & - & - & - & + & + & - & - & - & + & + & - \\
\hline 8 & - & + & + & + & - & - & - & + & + & + & - & - & - & + \\
\hline 9 & + & - & - & - & - & - & - & + & + & + & + & + & + & - \\
\hline 10 & + & - & - & + & - & - & + & + & - & - & + & - & - & + \\
\hline 11 & + & - & + & - & - & + & - & - & + & - & - & + & - & + \\
\hline 12 & + & - & + & + & - & + & + & - & - & + & - & - & + & - \\
\hline 13 & + & + & - & - & + & - & - & - & - & + & - & - & + & + \\
\hline 14 & + & + & - & + & + & - & + & - & + & - & - & + & - & - \\
\hline 15 & + & + & + & - & + & + & - & + & - & - & + & - & - & - \\
\hline 16 & + & + & + & + & + & + & + & + & + & + & + & + & + & + \\
\hline Kolon no & 1 & 2 & 3 & 4 & 5 & 6 & 7 & 8 & 9 & 10 & 11 & 12 & 13 & 14 \\
\hline
\end{tabular}


En Aw 5754 (Almg3) Alüminyum Alaşımının Frezelenmesi Işsleminde Kesme Parametrelerinin Yüzey Pürüzlülüğüne Etkisinin Incelenmesi

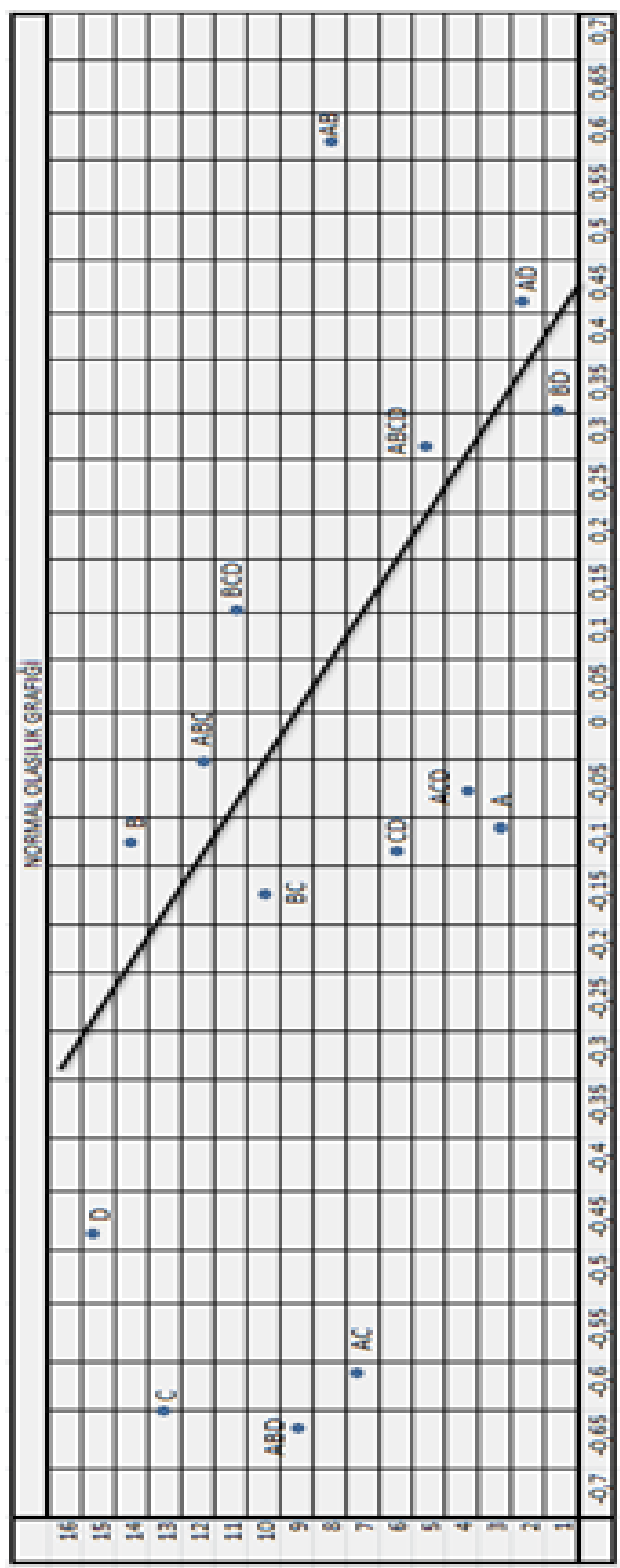

Şekil 5. Frezeleme işleminde işlem parametrelerinin yüzey pürüzlülük değerine etkilerine ait normal olasılık grafiği

Frezeleme işleminde devir sayısı ve ilerleme etkileşiminde kesici uç yarıçapı $1 \mathrm{~mm}$ ve $2 \mathrm{~mm}$ değerlerine karşıllı elde edilen yüzey pürüzlülüğü Ra değerleri Çizelge 7'de grafiksel gösterimi Şekil 6'da verilmiştir.
Çizelge 7. Frezeleme işleminde devir sayısı ve ilerleme etkileşiminde kesici uç yarıçapı $1 \mathrm{~mm}$ ve $2 \mathrm{~mm}$ değerlerine karşılık elde edilen yüzey pürüzlülüğü Ra değerleri

\begin{tabular}{|c|c|c|}
\hline \multirow{2}{*}{$\begin{array}{c}\text { B: İlerleme } \\
(\mathrm{mm} / \mathrm{dak})\end{array}$} & \multicolumn{2}{|c|}{$\mathrm{D}$ : Kesici uç yarıçapı $(\mathrm{mm})$} \\
\cline { 2 - 3 } & 1 & 2 \\
\hline \multirow{3}{*}{97} & $\operatorname{Ra}(\mu \mathrm{m})$ & $\operatorname{Ra}(\mu \mathrm{m})$ \\
& 0,63 & 2,6 \\
& 0,65 & 0,44 \\
& 0,81 & 0,3 \\
& 0,81 & 0,38 \\
& 0,73 & 1,03 \\
\hline \multirow{3}{*}{196} & $\mathrm{Ra}(\mu \mathrm{m})$ & $\operatorname{Ra}(\mu \mathrm{m})$ \\
& 2,43 & 0,91 \\
& 1,79 & 1 \\
& 2,3 & 0,83 \\
& 1,87 & 1,09 \\
& 2,1 & 0,96 \\
\hline
\end{tabular}

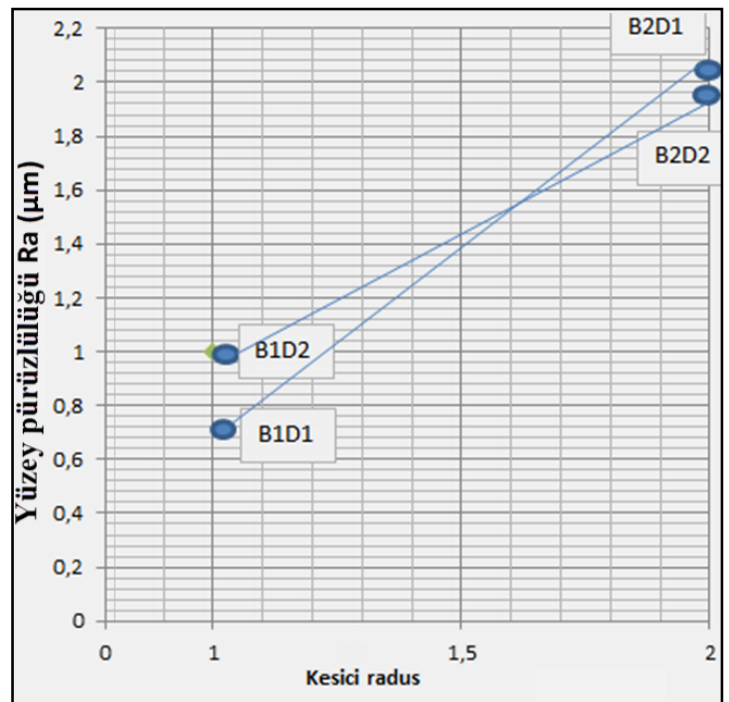

Şekil 6. İlerleme ile kesici uç yarı çapının yüzey pürüzlülük değerine etkisi

Şekil 6'da elde edilen veriler incelendiğinde ilerlemenin düşük seçilmesi durumunda kesici uç yarıçapının da küçük seçilmesi ile daha düşük yüzey pürüzlülüğü değerlerinin elde edilebileceğini göstermektedir. Yüksek ilerleme değerleri seçildiğinde ise kesici uç yarıçapının daha büyük seçilmesi yüzey pürüzlülük değerini düşürdüğü görülmektedir. $\mathrm{Bu}$ sonuçlar frezeleme işleminde daha iyi yüzey kalitesi elde etmek için ilerleme miktarı ile kesici uç yarıçapının orantılı olarak seçilmesi gerektiğini göstermektedir. 
Frezeleme işleminde olduğu gibi bağımsız değişkende (yüzey pürüzlülüğü - Ra) çok sayıda bağımlı değişkenin söz konusu olduğu durumlarda, parametre etkileşimlerinin sonuca etkisini analiz etmede varyans analizi (ANOVA) kullanılmaktadır. ANOVA bağımsız değişkenlerin kendi aralarında nasıl etkileşime girdiklerini ve bu etkileşimlerin bağımlı değişken üzerindeki etkilerini analiz etmek için kullanılmaktadır. Yapılan deneysel çalışmaların sonuçları ile oluşturulan ilerleme miktarı ile talaş derinliğinin yüzey pürüzlülüğüne etkisi Şekil 7'de, ilerleme ile devir sayısının yüzey pürüzlülüğüne etkisi Şekil 8'de, devir sayısı ile kesici uç yarıçapının yüzey pürüzlülüğüne etkisi Şekil 9'da görüldüğü gibi elde edilmiştir.

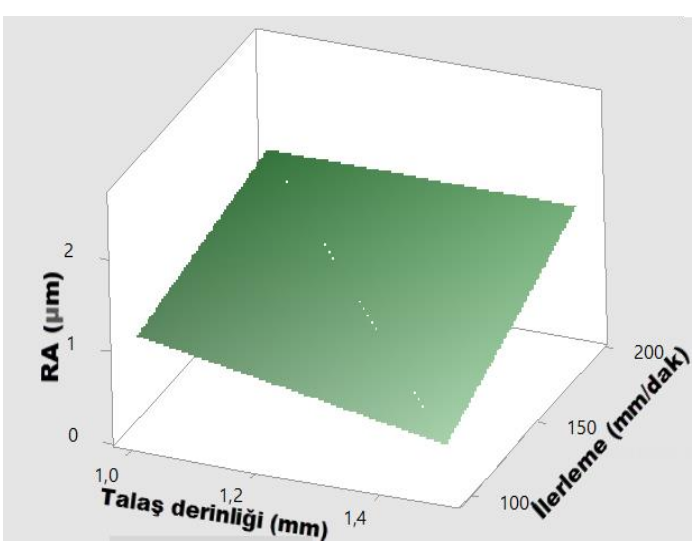

Şekil 7. İlerleme miktarı ile talaş derinliğinin yüzey pürüzlülüğüne etkisi

Şekil 7'deki veriler değerlendirildiğinde, talaş derinliği ile ilerleme miktarına bağlı olarak en uygun yüzey pürüzlülüğü, her iki parametrenin de düşük değerlerinde elde edilmektedir. Parametre değerleri yüksek alındığında yüzey pürüzlülük değeri de artmaktadır. Şekil 8 incelendiğinde devir sayısı ile ilerleme miktarına bağlı olarak en uygun yüzey pürüzlülügü, her iki parametrenin de düşük değerlerinde elde edildiği görülmektedir. Parametre değerleri yüksek alındığında yüzey pürüzlülük değerinin de arttığı görülmektedir. Şekil 9'daki veriler incelendiğinde devir sayısı ile kesici uç yarıçapına bağlı olarak en uygun yüzey pürüzlülüğü, devir sayısının düşük kesici uç yarıçapının ise büyük değerlerinde elde edildiği görülmektedir.

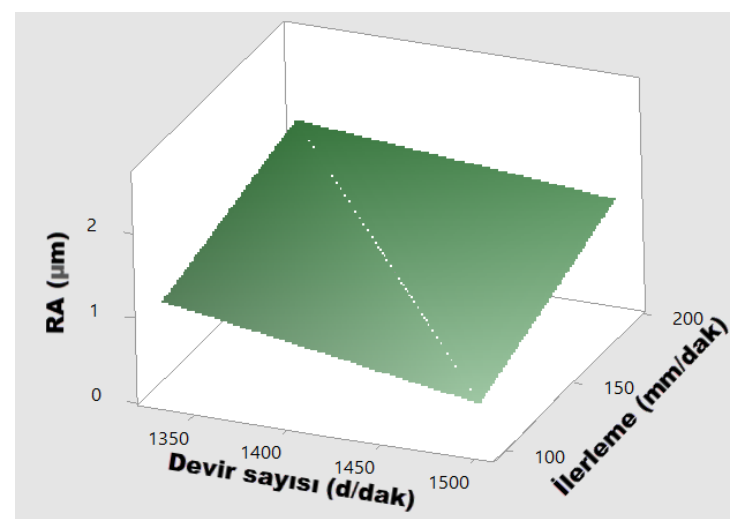

Şekil 8. Devir sayısı ile ilerleme miktarının yüzey pürüzlülüğüne etkisi

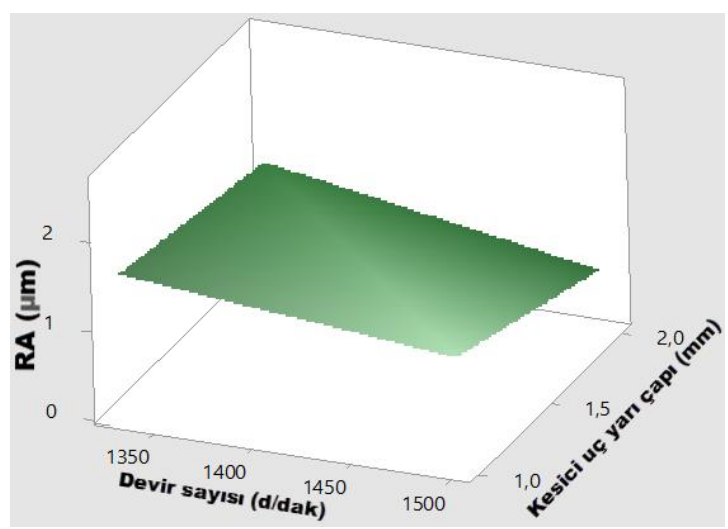

Şekil 9. Devir sayısı ile kesici uç yarı çapının yüzey pürüzlülüğüne etkisi

\section{TARTIŞMA VE SONUÇ}

Frezeleme işleminde daha iyi yüzey kalitesi elde etmek için ilerleme miktarı ile kesici uç yarıçapının orantılı olarak seçilmesi gerekmektedir.

Talaş derinliği ile ilerleme miktarına bağlı olarak en uygun yüzey pürüzlülüğü, her iki parametrenin de düşük değerlerinde elde edilmektedir. Talaş derinliği ile ilerleme miktarı değerleri yüksek alındığında yüzey pürüzlülük değeri de artmaktadir.

Devir sayısı ile ilerleme miktarına bağlı olarak en uygun yüzey pürüzlülüğü, her iki parametrenin de düşük değerlerinde elde edilmektedir. Devir sayısı 
ile ilerleme miktarı değerleri yüksek alındığında yüzey pürüzlülük değeri de artmaktadır.

Devir sayısı ile kesici uç yarıçapına bağlı olarak en uygun yüzey pürüzlülüğ̈̈, devir sayısının düşük kesici uç yarıçapının ise büyük değerlerinde elde edilmektedir.

\section{KAYNAKLAR}

1. Şirvanc1, M., 1997. Kalite için Deney Tasarımı, Literatür Yayınları, İstanbul, p. 110.

2. Scheffler, E.,1997. Statis Cheversych Planing und Austwertung, Eine Ein Führungindie Praxis der Statistichen Versuch planunug, Deutscher Verlogfür Grund staff industrie Stuttgard, ISBN 3-342-00366-9, p. 1-50.

3. Klimchik, A., Ambiehl, A., Garnier, S., Furet, B., Pashkevich, A., 2017. Efficiency Evaluation of Robot in Machining Applications using İndustrial Performance Measure, Robotics and Computer-Integrated Manufacturing, Vol. 48, p. 12-29.

4. Lunani, M.,Nair, V.N., Wasserman, G.S., 1997. Graphical Metods for Robust Design with Dynamic Characteristics, Journal of QualityTechnology, Vol.29, p. 327-338.

5. Montgomery, D.C.,1991. Design and Analysis of Experiment, John Wiley \& Sons, Newyork.

6. Ranjit, K.R., 1990. A Primer on the Taguchi Method: Van Nostrand Reinhold.

7. John, P., Davis, R., 2016. Performance Study of Electrical Discharge Machining Process in Burn Removal of Drilled Holes in Al 7075, Cognet Engineering, Vol. 3, p.1-7.

8. Gökçe, G, Taşgetiren, S., 2009. Kalite için Deney Tasarımı Makine Teknolojileri Elektronik Dergisi. Cilt:6,No:1,p. 71-83.

9. Ross, W., Sykes, S., 1989. Optimization of a Hot-stampingprocess, American Supplier Institute Inc., Michigan.

10. Dovey, S.J., Matthews, A., 1998. Taguchi and TQM Quality Issues for Surface Engineered Applications, Research Centre in Surface Engineering, Universitiy of Hull, Surface and Coatings Technology Hull.

11. Auroux, D., Groza, V., 2016. Optimal Parameter Sidentification and Sensitivity Study for Abrasive Water Jet Milling Model, Inverse Problems in Science and Engineering, p. 1-17.

12. Kağnıcıŏglu, C.H., 1998. Üretim Öncesi Kalite Kontrolünde Taguchi Yöntemi ve Kükürtdioksit Giderici Sitrat Yöntemine Uygulanması, Anadolu Üniversitesi, Sosyal Bilimler Enstitüsü, İşletme Anabilim Dalı, Doktora Tezi, p. $216 \mathrm{~s}$. 